1. A graphic clinical lecture on a case of Diabetic Paraplegia due to Peripheral Neuritis, by Professor Charcot. 2. A minute account of the Lesions in Friedreich's Disease, by MM. Blocq and Marinesceo. 3. An Experimental Investigation of the Psychological Process described as Unconscious Perception, by M. Ouanoff. 4. Pathological Observations on cases of Postero-lateral Sclerosis, by M. Francotte of Liége. 5. A digest of Recent Literature on Mental Disease. 6. A Report of the Proceedings of the various Societies in France especially interested in Neurology.

Official Year-book of the Scientific and Learned Societies of Great Britain and Ireland for 1890. C. Griffin and Co.The information contained in this annual is obtained from official sources, and includes a record of all the work done by the learned Societies engaged in fourteen departments of scientific research, as well as a concise review of the history, organisation, and conditions of membership of the various scientific and learned Societies throughont the British isles. As a book of reference we have ever found it trustworthy.

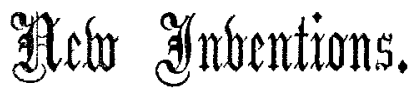

\section{A NEW FORM OF EYELID RETRACTOR.}

THE difficulty in examining the eye in children is often very great, especially in cases of corneal ulcers, ophthalmia neonatorum, or any affection of the eye attended with photophobia. The accompanying woodcut illustrates a new form of lid retractor which overcomes the difficulty to a great extent, and makes such an examination very simple. There are two retractors, each an inch and a quarter long, but having the rings different in size, the larger ring being intended to fit the distal phalanx of either thumb, and the smaller ring to fit any finger. Both lids can easily be separated by means of the two retractors, the one applied to the thumb and the other to the index finger of the same hand, chus leaving the remaining fingers of that hand and the

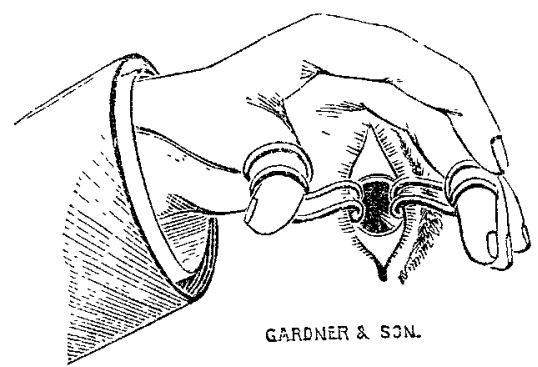

other hand perfectly free. In the common form of lid retractor two or three fingers are required for each retractor, and if both lids are to be separated so as to obtain a com. plete view of the eye, the surgeon requires both hands for the retractors, thus excluding him from being able to use any application to the eye which he may think necessary. By means of this simple form of retractor which I have described, both lids can be separated by the thumb and index finger of one hand, thus leaving the other hand entirely free, and at the same time being able to steady the head with the palm of the hand, holding the retractors and the remaining fingers of the same hand. These retractors enable the surgeon to obtain a very complete view of the front of the eye, especially when he is provided with no assistance except that of the nurse. The instrument has ween made for me by Messrs. Gardner and Son, Edinburgh. Dundee.

Angus McGillivray, C.M., M.B.

\section{A NEW PORTABLE OPERATION TABLE.}

THE operation table here figured has been devised by me to meet what I think is universally considered to be a great want in the profession--a want equally felt by the surgeon, gynæcologist, and general practitioner. The surgeon and gynæcologist, going from place to place, are often put to great straits for the want of a suitable table to operate on; and for small operations performed in the consulting rooms a table that can be put up in a minute, and when not required can be packed away in a small space, must be a great desideratum. The general practitioner, who so frequently has cases of accident brought to his surgery, neces-

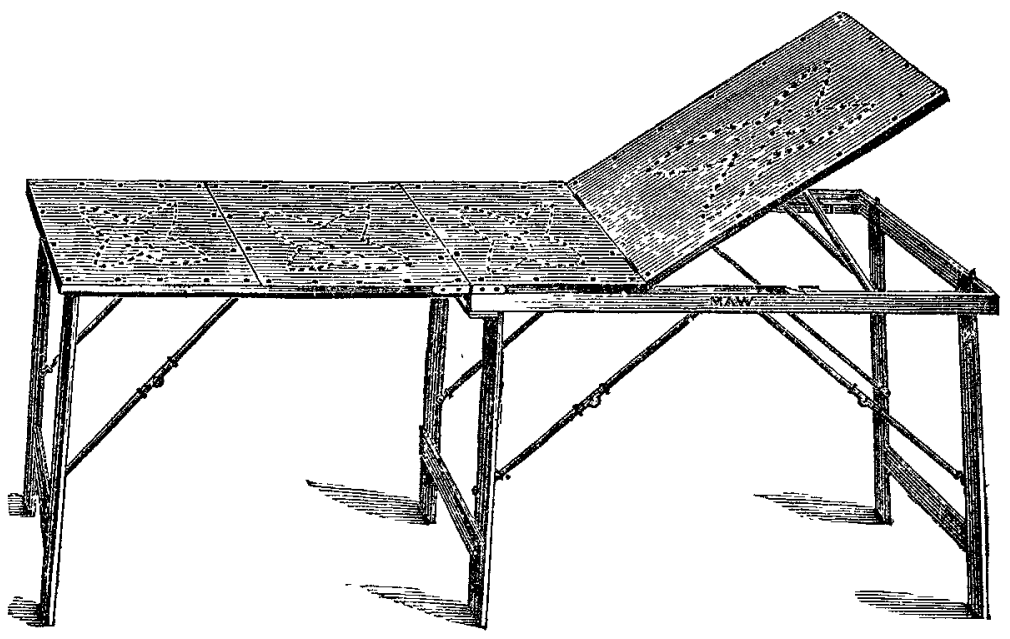

sitating careful examination, the performance of some minor operation, or the putting up of a fracture \&c., has at present to do so at great personal inconvenience for the want of a suitable table on which to place the patient. For surgical homes, where the operation table has to be taken frorn room to room, such a table will avoid an infinity of labour. The woodcuts show the table in different positions. Messrs. Maw, Son, and Thompson, Aldersgate-street, have carried out my suggestions most carefully and successfully. When opened, the table measures $5 \mathrm{ft} .9$ in. in length, $1 \mathrm{ft} .8$ in. wide, and $2 \mathrm{ft} .8 \mathrm{in}$. high. The lower flap can be let down, and the legs and framework supporting it telescoped into the upper portion of the table; the crutches being applied, the patient can be put into

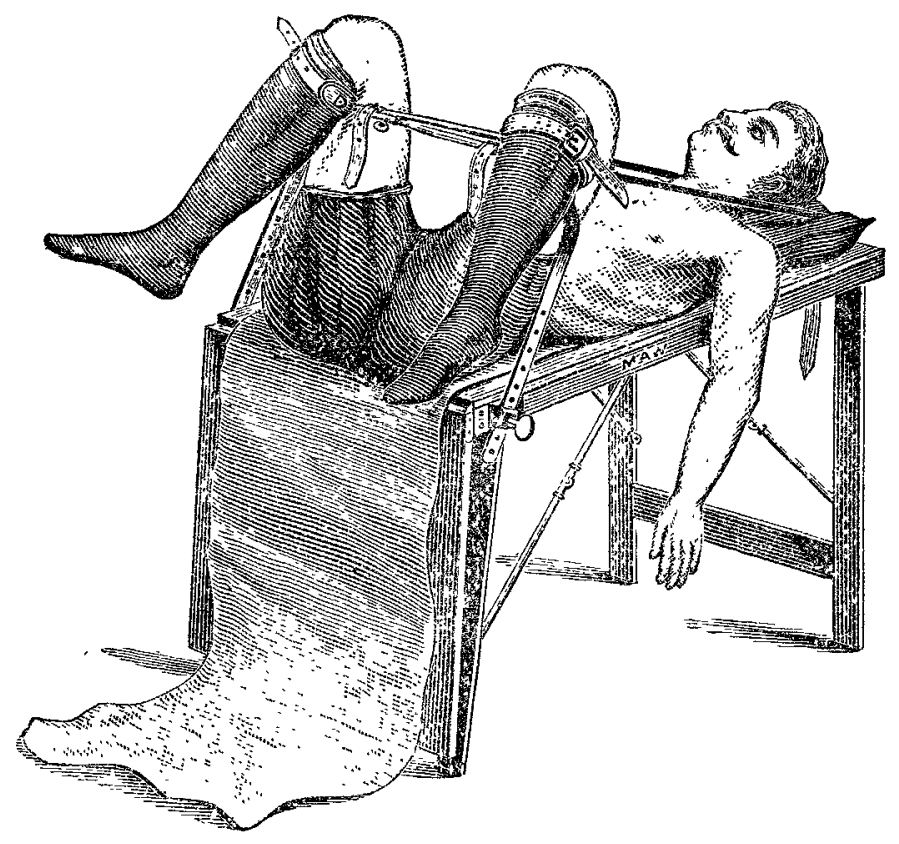

lithotomy position, the crutch being fixed by means of straps which are fastened to the upper end of the table, thereby avoiding all pressure on the patient's chest, which is an objection to Clover's crutch. When not in use, the table is packed in a strong canvas bag, and weighs a little over 30 lb. ; its dimensions thus being 35 in. by 20 in., and $3 \frac{1}{2}$ in thickness, so that it can be readily carried, and easily put into any carriage or cab. The advantages clainued for the table are lightness, stability, simplicity, compactness, and perfect adaptability to meet all requirements of the surgeon, gynæecologist, and general practitioner; coupled with these advantages, its cost is small, being about half of that charged for any other operation table or gynæcological chair I know of.

Upper Wimpole-street, $W$.
Freid. B. JessetT. 